\title{
Michel Cotte, De l'espionnage industriel à la veille technologique
}

Belfort, Presses universitaires de Franche-Comté, collection «Sciences humaines et technologie », 2005, 294 pages, bibliographie, index.

\section{André Guillerme}

\section{(2) OpenEdition}

Édition électronique

URL : http://journals.openedition.org/dht/1130

DOI : $10.4000 /$ dht. 1130

ISSN : 1775-4194

Éditeur :

Centre d'histoire des techniques et de l'environnement du Cnam (CDHTE-Cnam), Société des élèves du CDHTE-Cnam

\section{Édition imprimée}

Date de publication : 1 décembre 2007

Pagination : 154-155

ISBN : 978-2-9530779-0-2

ISSN : 0417-8726

Référence électronique

André Guillerme, « Michel Cotte, De l'espionnage industriel à la veille technologique », Documents pour I'histoire des techniques [En ligne], 14 | $2^{\mathrm{e}}$ semestre 2007, mis en ligne le 03 novembre 2010, consulté le 24 septembre 2020. URL : http://journals.openedition.org/dht/1130; DOI : https://doi.org/10.4000/ dht. 1130

Ce document a été généré automatiquement le 24 septembre 2020.

(c) Tous droits réservés 


\section{Michel Cotte, De l'espionnage industriel à la veille technologique}

Belfort, Presses universitaires de Franche-Comté, collection « Sciences humaines et technologie ", 2005, 294 pages, bibliographie, index.

\section{André Guillerme}

\section{RÉFÉRENCE}

Michel Cotte, De l'espionnage industriel à la veille technologique, Belfort, Presses universitaires de Franche-Comté, collection « Sciences humaines et technologie », 2005, 294 pages, bibliographie, index.

1 Dans cet ouvrage neuf, clair, posé, synthétique, Michel Cotte se charge d'une mission modératrice : saisir les manières d'échanger les techniques industrielles entre firmes, États, individus, observer la circulation des savoirs. Questions d'actualité du monde industriel contemporain que l'auteur ne cesse de côtoyer. Historien des techniques à l'université de Nantes, il présente au public averti en partie son mémoire d'habilitation élaboré depuis sa thèse brillamment soutenue sous la direction de Louis Bergeron relative à l'entreprise Seguin qui édifie, dans les années 1820, les premiers ponts suspendus français, construit la première ligne ferroviaire, invente la chaudière tubulaire et ménage la première gare en périphérie urbaine. Seguin inventeur, innovateur, copieur, transmetteur, adaptateur; Michel Cotte a déjà montré que l'entrepreneur est tout cela à la fois parce qu'il n'a jamais cessé de constituer un réseau de relations internationales techniques, commerciales, politiques, parentales - avec ses oncles les Montgolfier, avec ses frères, ses fils et ses brus.

2 À cette première constitution du nouveau savoir, Michel Cotte adjoint les voyages d'affaires et les missions publiques (chap. 5). "Les voyages forment l'industrie", pourrait-on résumer. Depuis la fin du XVIIe siècle, les princes - tsar, rois de Prusse et de France - commettent leurs lettrés, les attachent aux ambassades pour collecter des informations toujours plus techniques, sorte de « reconnaissance » que savent réaliser 
les ingénieurs militaires pour préparer la bataille ou le siège. Avec les Lumières, avec la domination britannique, avec l'agressivité commerciale, la fréquence augmente, l'enjeu devient plus savant. Les Français débarquent outre-Manche, visitent ports et arsenaux, notent et annotent, questionnent, dessinent, rencontrent, échangent, partagent : il n'y a pas réellement espionnage, ni entraide; mais curiosité, comparaison, sympathie. À part ces voyages officiels, ces raisons d'État, qui continuent aujourd'hui - le plus grand flux de missionnaires français a lieu entre 1945 et 1949 vers les États-Unis et l'URSS les voyages d'information, privés, se déploient surtout dans le dernier tiers du XVIIIe siècle. Ils sont le fait de gros entrepreneurs et de commerçants chargés de prospecter le marché, d'établir des dépôts et des entrepôts, des contacts locaux, des liens avec les acteurs de l'économie, pour étoffer leurs affaires. Ils constituent, dans le territoire à entreprendre, des "réseaux maillés" au sens technique du terme - connexions non ordonnées, isotropie des informations, densité des flux et des contacts - qui sont bien mis en évidence, ici.

3 La culture technologique est l'autre terre que laboure Michel Cotte : formation initiale des ingénieurs et des entrepreneurs (chap. 4), formation continue - l'édition technique et scientifique - (chap. 3). L'écrit, devenu primordial dans la transmission du savoir technique, s'étoffe dans les encyclopédies, les journaux savants et de haute vulgarisation, les revues de curiosités, d'abord à Paris, capitale des lettres et mégapole manufacturière, puis dans les cités industrielles, Mulhouse, Lyon, Rouen. Le Bulletin de la Société d'Encouragement pour l'Industrie nationale, les Annales des Ponts et Chaussées et les Annales de l'Industrie nationale et étrangère sont présentés et commentés. Les traductions d'ouvrages (pp. 86-88) sont particulièrement bien venues pour comprendre la diffusion des connaissances, comme l'analyse du contenu de la bibliothèque de la Société industrielle de Mulhouse, lors de sa constitution, dans les années 1825-1830 (pp. 89-92). Les études secondaires dans des écoles religieuses assoient la culture initiale des entrepreneurs et assurent les premiers réseaux de relation - l'amitié se durcit sous la discipline du maître. Mathématiques, latin, chimie, dessin auxquels s'ajoutent la lecture et l'écriture. Polyvalence plus que polytechnique. Les plus motivés préparent les grandes écoles ou fréquentent les officines urbaines des chimistes ou des appareilleurs ; tous voyagent dans la région d'origine d'abord, plantent quelques racines, dans le pays ensuite, à Paris toujours, puis à l'étranger, outre-Manche, Rhin, montagne.

4 La culture mécanique britannique (chap. 6) "dé-chaîne » le mouvement industriel en France (chap. 2). Michel Cotte rend visite à nouveau à ces capitaines anglais, filateurs, équipementiers, machinistes, francophiles et francophones qui s'installent ici pour y monter des usines : Manby et Wilson, futurs gestionnaires du Creusot, Collins, Edwards, etc. Il esquisse une géographie de l'innovation industrielle du premier XIXe siècle : les ports maritimes - Lorient, Cherbourg, Rouen, Nantes, Marseille - et certaines régions entre Lyon et Saint-Étienne, Lille et Amiens, Mulhouse et Bâle. À cette lecture, on subodore un aménagement du territoire, une pensée et une action politiques, révélées au moins dans De l'industrie française de Chaptal. Cette gouvernance industrielle française est lue au travers de la Société d'encouragement, ses brevets protégés, ses émulations, prix et médailles, les expositions parisiennes nationales, les collections. Le mouvement s'amplifie tout au long du siècle et s'internationalise. Gardons-nous cependant d'y voir un enthousiasme forcené.

5 Dans le dernier tiers de sa recherche, Michel Cotte voyage outre-Manche et outreAtlantique, en anglophonie : comment s'y organisent les institutions et les formations - 
il rend compte de la Société des ingénieurs civils britannique créée en 1824 techniques; comment y sont perçues les techniques étrangères entre libéralisme et protectionnisme. Comment le nouveau monde se saisit des ingénieurs européens pour inscrire les infrastructures viaires dans le territoire, gages de prospérité. Un bel ouvrage qui aurait mérité quelques illustrations.

\section{AUTEURS}

\section{ANDRÉ GUILLERME}

CDHTE-Cnam 